\title{
Contribution of Atmospheric Advection to the Amplified Winter Warming in the Arctic North Atlantic Region
}

\author{
Sandro Dahlke $e^{1,2}$ and Marion Maturilli ${ }^{1}$ \\ ${ }^{1}$ Alfred Wegener Institute, Helmholtz Centre for Polar and Marine Research, Potsdam, Germany \\ ${ }^{2}$ Institute of Physics and Astronomy, University of Potsdam, Potsdam, Germany \\ Correspondence should be addressed to Sandro Dahlke; sandro.dahlke@awi.de
}

Received 13 July 2017; Accepted 26 October 2017; Published 20 November 2017

Academic Editor: Annalisa Cherchi

Copyright (c) 2017 Sandro Dahlke and Marion Maturilli. This is an open access article distributed under the Creative Commons Attribution License, which permits unrestricted use, distribution, and reproduction in any medium, provided the original work is properly cited.

\begin{abstract}
Arctic Amplification of climate warming is caused by various feedback processes in the atmosphere-ocean-ice system and yields the strongest temperature increase during winter in the Arctic North Atlantic region. In our study, we attempt to quantify the advective contribution to the observed atmospheric warming in the Svalbard area. Based on radiosonde measurements from Ny-Ålesund, a strong dependence of the tropospheric temperature on the synoptic flow direction is revealed. Using FLEXTRA backward trajectories, an increase of advection from the lower latitude Atlantic region towards Ny-Ålesund is found that is attributed to a change in atmospheric circulation patterns. We find that about one-quarter $(0.45 \mathrm{~K}$ per decade) of the observed atmospheric winter near surface warming trend in the North Atlantic region of the Arctic ( $2 \mathrm{~K}$ per decade) is due to increased advection of warm and moist air from the lower latitude Atlantic region, affecting the entire troposphere.
\end{abstract}

\section{Introduction}

It is well known that the Arctic is warming faster than any other place on the globe [1], a phenomenon referred to as Arctic Amplification [2]. Yet, the Arctic warming is by no means uniform but occurs strongest in the winter months and close to the surface [3-5]. Furthermore, it is not equally distributed over the polar cap but strongly varies spatially, with the largest warming rates observed over the Barents/Kara Seas, consistent with the region of the strongest autumn and winter sea-ice retreat [6]. However, even at tropospheric levels there is a significant warming signal in recent decades that peaks in the Svalbard region in the North Atlantic part of the Arctic (Figure 1).

While several feedback mechanisms contribute to the Arctic Amplification of global warming, the relative importance of each contribution is still under discussion. While the sea ice-albedo feedback is often proposed as the main driver of Arctic warming (e.g., [2-4]), there is increasing evidence that excessive polar amplification can be accomplished even in the absence of a varying albedo [7-10]. Other important feedback processes are related to the warming effect of clouds in the Arctic [11], as an increasing cloud fraction and more abundant water vapor have an impact on the downward long-wave radiation in the Arctic winter $[3,6,12,13]$. Sources of increasing atmospheric water vapor are either local evaporation mostly over the ice-free ocean [14] or stronger moisture advection from lower latitudes [15-17]. Synopticscale intrusions of warm and moist air masses into the Arctic appear as extreme events related to blocking situations of the large scale circulation $[18,19]$. Overall, changes in the atmospheric circulation can accelerate Arctic warming by an advective contribution [19-21]. Here, we quantify to what extent the most recent (1996-2016) winter warming found in the Svalbard region, which is the region of the strongest Arctic winter warming, can be attributed to a shift in atmospheric circulation that facilitates the advection of anomalously warm air masses from the lower latitude Atlantic region.

\section{Data and Methodology}

2.1. Local Effect on Synoptic Flow. Focusing on the Arctic North Atlantic region in winter, long-term radiosonde observations from Ny-Ålesund, Svalbard [21], are employed to 


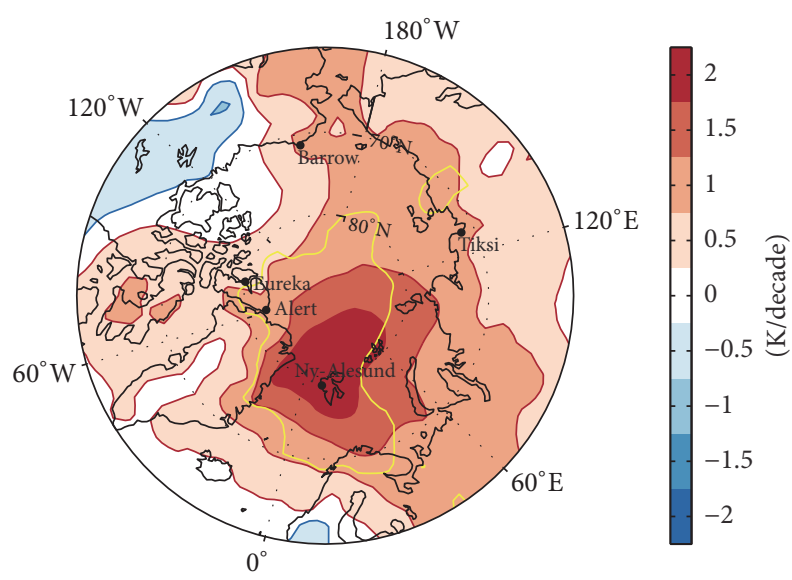

FIgURE 1: December-January-February (DJF) mean decadal temperature trend at the $850 \mathrm{hPa}$ level using ERA-Interim 1996-2016. Regions of significant trends ( $95 \%$ confidence level) are bounded by a yellow line.

analyze changes in the free troposphere. While the atmospheric boundary layer at Ny-Ålesund is strongly affected by orography, the vertical profiles from radiosonde measurements above the approximately $1 \mathrm{~km}$ high mountain ridges have been found to be representative for the large scale synoptic flow of the broader Arctic North Atlantic region [22].

Since also the poleward moisture transport at $70^{\circ} \mathrm{N}$ has been found to peak in the lower troposphere around $850 \mathrm{hPa}$ [23], we focus our analysis on this altitude range where large advective effects can be expected. The seasonal cycle of the mean $800-850 \mathrm{hPa}$ temperature from the 1993 to $2016 \mathrm{Ny}$ Ålesund radiosondes for different synoptic flow conditions (Figure 2(a)) reveal a strong impact of the flow direction. While easterly and westerly winds have no clear impact, there are distinctively higher temperatures apparent throughout the year during southerly winds (S) compared to northerly winds $(\mathrm{N})$, with the strongest southerly minus northerly ( $\mathrm{S}$ $-\mathrm{N}$ ) differences in winter exceeding $+8 \mathrm{~K}$. This difference reflects the contrast between advection of either warm moist Atlantic air from the south or cold dry Arctic air from the north towards $\mathrm{Ny}$-Ålesund. Using ERA-Interim reanalysis data [24] at $2^{\circ}$ spatial resolution for the same analysis yields similar results (see Figure S1 in Supplementary Material available online at https://doi.org/10.1155/2017/4928620), thus providing a suitable data base to examine the $\mathrm{S}-\mathrm{N}$ relationships for other prominent research stations along the Arctic basin rim. Both the mean $800-850 \mathrm{hPa}$ temperature and the integrated water vapor content (IWV) up to $200 \mathrm{hPa}$ were analyzed for DJF under different flow conditions at the closest land grid point for the Arctic stations $\mathrm{Ny}$-Ålesund $\left(78.9^{\circ} \mathrm{N}\right.$, $\left.11.9^{\circ} \mathrm{E}\right)$, Alert $\left(82.5^{\circ} \mathrm{N}, 62.3^{\circ} \mathrm{W}\right)$, Eureka $\left(80.0^{\circ} \mathrm{N}, 86.0^{\circ} \mathrm{W}\right)$, Barrow $\left(71.3^{\circ} \mathrm{N}, 156.6^{\circ} \mathrm{W}\right)$, and Tiksi $\left(71.6^{\circ} \mathrm{N}, 128.9^{\circ} \mathrm{E}\right)$, respectively. The difference between southerly and northerly flow conditions at the different sites is shown in Figure 2(b), and their geographical location is indicated in Figure 1. An Arctic-wide map showing the respective difference between southerly and northerly flow for all ERA-Interim grid points is provided in Figure S2. Ny-Ålesund stands out with the strongest positive southerly minus northerly $(\mathrm{S}-\mathrm{N})$ differences for both temperature $(+8.7 \mathrm{~K})$ and IWV $\left(+3.8 \mathrm{~kg} / \mathrm{m}^{2}\right)$, with only Barrow, Alaska, showing comparable $\mathrm{S}-\mathrm{N}$ differences of $+8.1 \mathrm{~K}$ and $+2.5 \mathrm{~kg} / \mathrm{m}^{2}$, respectively. This implies that the climate of the Svalbard region, center of the strongest recent winter warming (Figure 1), is particularly sensitive to changes in the atmospheric circulation. In order to quantify how much of the Svalbard warming signal is caused by a potential increase of advection from the south due to circulation changes, an air mass back trajectory study was applied to the Ny-Ålesund station data.

2.2. Trajectory Study. To identify changes in the source regions of air masses reaching Ny-Ålesund, FLEXTRA trajectory data [25] covering the years 1996 to 2016 were analyzed for the winter period December, January, and February (DJF). These FLEXTRA 3-dimensional backward trajectories are based on 6-hourly meteorological analyses at $1.125 \times$ 1.125-degree resolution, provided by the European Centre for Medium Range Weather Forecast (ECMWF). To avoid capturing boundary layer processes, trajectory endpoints were chosen at $1500 \mathrm{~m}$ height, being well above the local orography and within the free tropospheric flow. Geographically, the trajectory endpoints are located above Mount Zeppelin station, about $2 \mathrm{~km}$ south of the $\mathrm{Ny}$-Ålesund balloon launch platform. From these defined $\mathrm{Ny}$-Ålesund endpoints, the air mass trajectories are followed backwards for 3 days where the starting position is referred to as the "source region" of $\mathrm{Ny}$ Alesund air. For the statistical analysis of the trajectories, a circular area with radius $300 \mathrm{~km}$ was defined around each grid point on a $1 \times 1$-degree longitude-latitude grid, and the number of trajectory starting points within each circle was counted. Clearly, the probability to be source region for Ny-Ålesund air is the highest (about 3\% per circle) in the Svalbard region itself (Figure 3(a)). However, it is noteworthy that there is a nonzero chance that the air has originated in very distant midlatitude source regions, especially in the Atlantic/European sector.

\section{Results}

3.1. Changes in Source Regions of Ny-Ålesund Air. By dividing the FLEXTRA period in two subperiods P1 (Dec. 1996-Feb. 2006) and P2 (Dec. 2006-Feb. 2016), a change in the occurrence frequency of source regions is identified (Figure 3(b)). Between the first (P1) and the second (P2) decade, there is a substantial increase in days when the midlatitude North Atlantic region was source region for $\mathrm{Ny}$-Ålesund air. At the same time, wide parts of the Arctic basin's rim are governed by negative differences, implying a reduced impact of air from these regions in the more recent period in $\mathrm{Ny}$-Ålesund. Statistical significance of the change in source region is estimated by a Monte Carlo simulation, where all DJF trajectories were subsampled in two subgroups $\mathrm{P}_{\mathrm{G} 1}$ and $\mathrm{P}_{\mathrm{G} 2}$, each randomly containing 10 years of data. This subsampling was repeated 10000 times and the resulting maps of changes in the source regions were compared to the original decomposition into P1 and P2. 


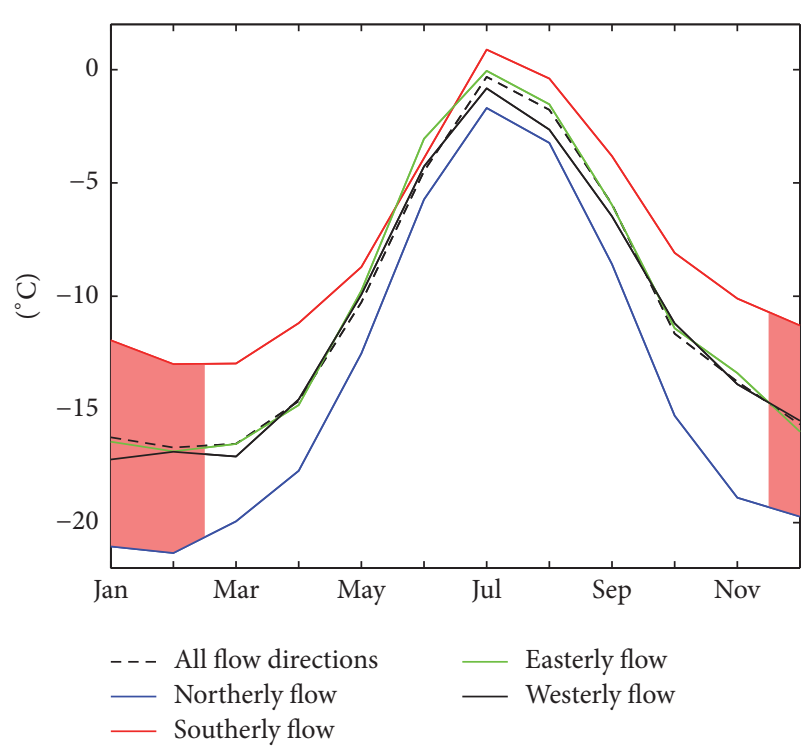

(a)

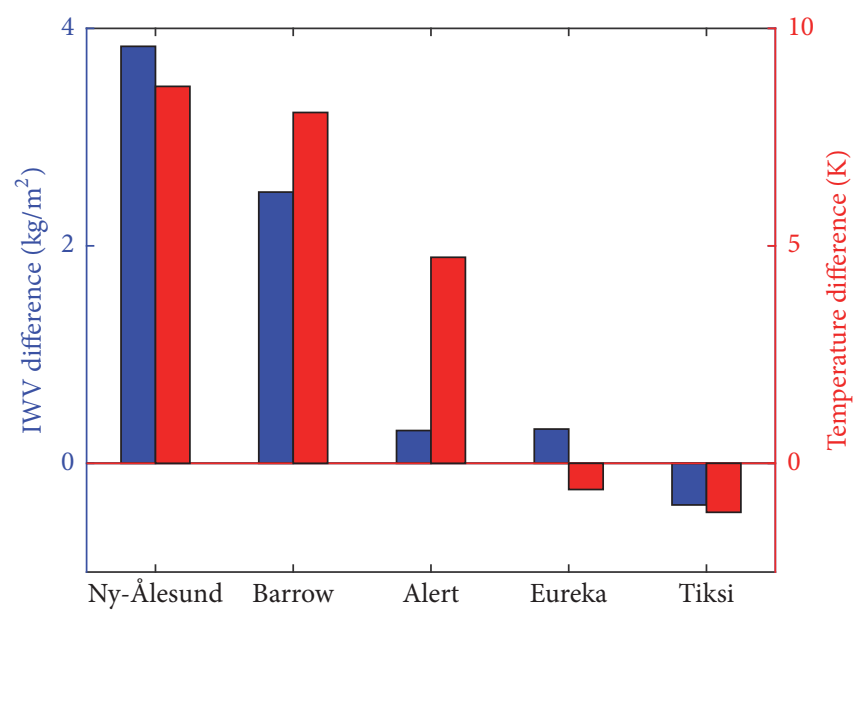

(b)

FIGURE 2: (a) Ny-Ålesund temperature from radiosondes 1993 to 2016 averaged between 800 and 850 hPa for different flow directions. Cardinal wind directions were defined as perfect $\pm 45^{\circ}$ and at least $75 \%$ of winds in the layer had to be within that range. The $\mathrm{S}-\mathrm{N}$ difference during DJF is shaded. (b) $\mathrm{S}-\mathrm{N}$ difference in temperature (red, averaged between 800 and $850 \mathrm{hPa}$ ) and water vapor content (IWV, blue, vertically integrated up to $200 \mathrm{hPa}$ ) for different Arctic locations from the ERA-Interim reanalysis during DJF.

To describe the region of increased source region probability over the Atlantic we define an "Atlantic Box" (ATL box) that stretches from $45^{\circ} \mathrm{W}$ to $20^{\circ} \mathrm{E}$, and from $50^{\circ} \mathrm{N}$ to $71^{\circ} \mathrm{N}$, respectively (Figures $3(\mathrm{~b})$ and $3(\mathrm{c})$ ). Overall, the ATL box was source region to $\mathrm{Ny}$-Ålesund air in 16\% (21\%) of all days in P1 (P2), representing a relative increase of about $30 \%$. This increase is particularly interesting, as the whole ATL box source region is associated with the above average temperatures in Ny-Ålesund (Figure 3(c)). On average, trajectories were $5.5 \mathrm{~K}$ warmer when arriving at the $\mathrm{Ny}$-Ålesund endpoint in cases when the ATL box was the source region of the air, compared to when it was not, clearly depicting the profound impact of marine air mass advection from the south during winter.

3.2. Circulation Changes. In a next step, it is investigated whether there have been systematical changes in the large scale circulation that explain the enhanced occurrence frequency of the ATL box source region in the recent decade. Considering all time steps when the source region of $\mathrm{Ny}$ Ålesund air was identified in the ATL box, a composite of sea level pressure (SLP) fields has been derived from the ERAInterim reanalysis. The resulting pattern is shown together with the DJF mean SLP pattern in Figure 4(a). Climatological features like the Icelandic and the Aleutian Low, as well as the Siberian High, are identified. Regarding the ATL box SLP composite, two large scale features stand out: a negative anomaly centered over Greenland, associated with an intensified Icelandic Low, and a positive SLP anomaly centered over Scandinavia and northwestern Russia, associated with the socalled Ural blocking [26]. Anomalies for both features reach amplitudes of $\pm 8 \mathrm{hPa}$, and the entire SLP composite pattern is significantly different from zero at the $99 \%$ confidence level (not shown, two-sided Student's $t$-test). From a geostrophic point of view, this composite SLP pattern allows very effective "pumping" of air masses from the midlatitude Atlantic region into the North Atlantic part of the Arctic, with Svalbard located in the advection key region. At the same time, the pattern is geostrophically consistent with reduced advection of cold air masses from northern Siberia towards Svalbard, as implied by Figure 3(b). Hence, if the pattern occurred more frequently in $\mathrm{P} 2$ than in $\mathrm{P} 1$, it would represent a dynamical atmospheric contribution to the Arctic Amplification in the North Atlantic Arctic. To describe the state of the composite SLP pattern over time, its 6-hourly index was computed in the following way. The positive part of the SLP composite pattern $(p>2 \mathrm{hPa}$ ) was extracted by setting values $<2 \mathrm{hPa}$ to zero. At every grid point, the remaining composite was then weighted by the cosine of the latitude and with respect to its amplitude, as well as normalized such that the sum over all grid points equals one. This normalized pattern was then multiplied by the 6-hourly SLP anomaly field and spatially averaged at every time step to yield one index value per time step. Similarly, an index for the negative part of the SLP composite pattern $(p<$ $-2 \mathrm{hPa}$ ) was derived. The final index results from subtracting the normalized negative from the normalized positive pattern index. We smoothed the index using a zero phase-shift Butterworth filter, with a cutoff frequency of $3 * 90=270$ days, which to a good approximation translates to a 3-year low pass filter in terms of consecutive DJF data. The retrieved time series of this SLP composite pattern index (Figure 4(b)) reveals interannual and decadal variability. Most strikingly, while the index was mainly in its negative phase during the first period P1, the index was mostly in its positive phase 

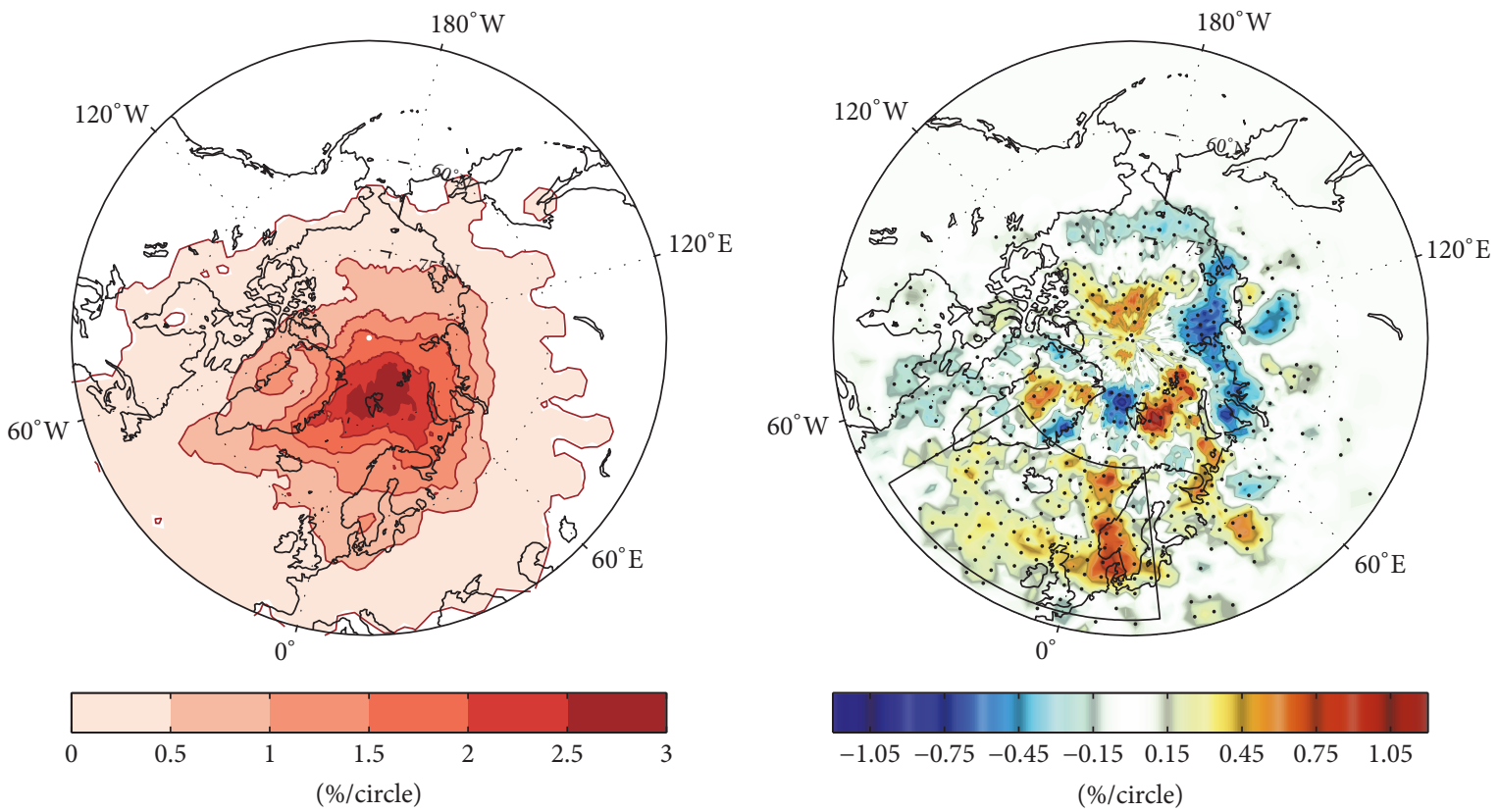

(a)

(b)

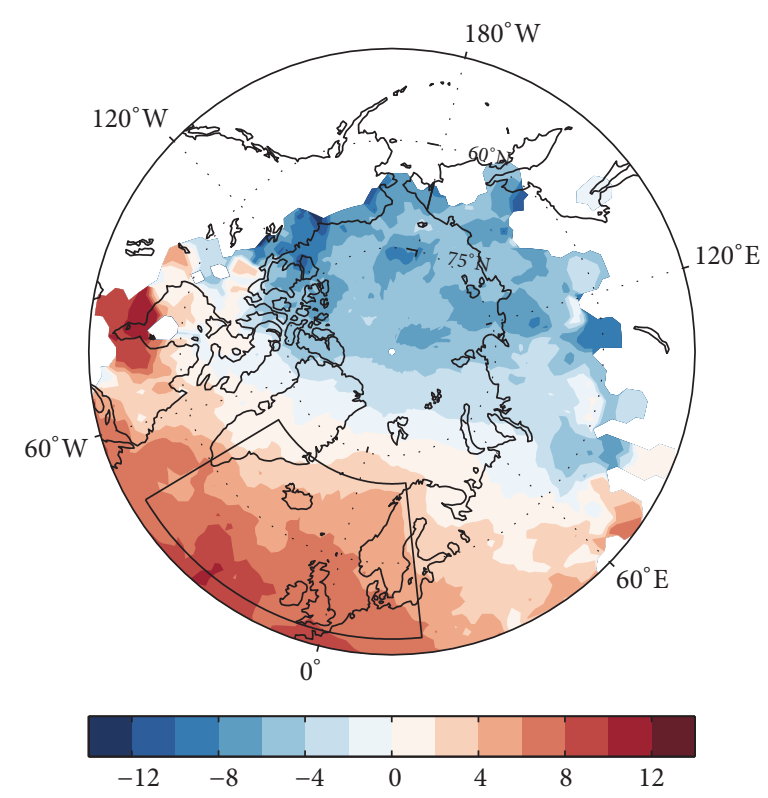

(K)

(c)

Figure 3: (a) Probability distribution map for DJF source regions of Ny-Ålesund air at $1500 \mathrm{~m}$ height. (b) Change in probability expressed as difference P2 (Dec. 2006-Feb. 2016) minus P1 (Dec. 1996-Feb. 2006). Statistical significance (99\%) is indicated by dots and only shown for changes exceeding $\pm 0.1 \% /$ circle (see text for details). (c) Ny-Ålesund temperature anomaly as a function of source region. The ATL box (see Section 3.1) is drawn in panels (b) and (c).

during the later period $\mathrm{P} 2$, owing to a strong increase from the year 2004 to around 2012. In terms of geostrophic transport, this finding confirms the more frequent advection of air masses from the ATL box in the later decade P2 compared to the earlier decade P1 (Figure 3(b)). We emphasize that although the negative part of the SLP composite pattern in Figure 4(a) bears some similarity to the negative pole of the
North Atlantic Oscillation (NAO, [27]), the positive anomaly over Scandinavia/northwestern Russia is clearly distinct from the classical NAO pattern. This is an indication that both parts of the composite pattern are important to describe its state, which strongly determines the meridional distribution of warm and moist air towards Svalbard and the North Atlantic region of the Arctic. 


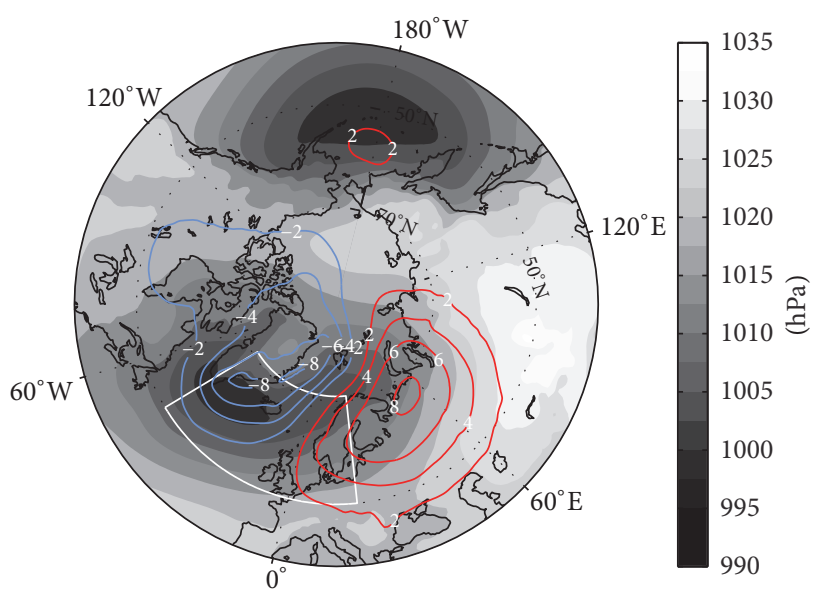

(a)

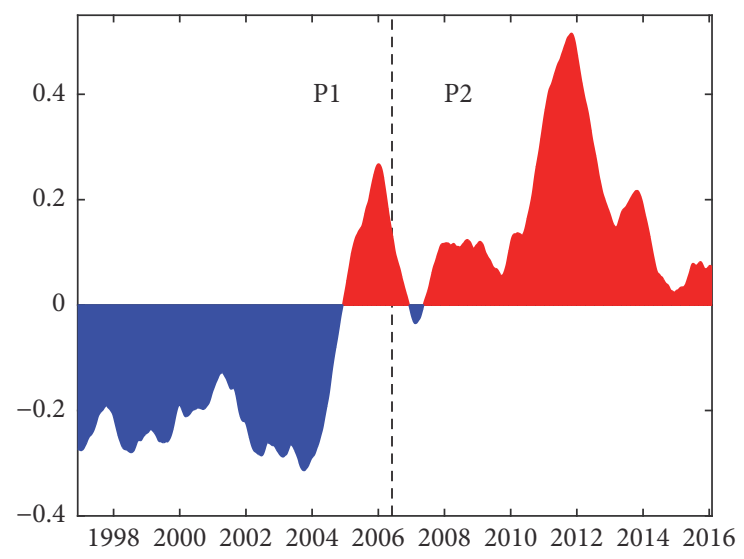

(b)

FIgURE 4: (a) Climatological SLP during DJF 1996-2016 (gray shading) and SLP composite during ATL Box trajectories arriving in NyÅlesund (hPa, color contours). (b) Normalized time series of the DJF SLP composite pattern shown in (a) with a three-year low pass filter applied (see text for details).

3.3. Quantification of Advective Warming. Finally, we extract the amount of Arctic winter warming that occurs solely as a consequence of enhanced advection of air from the lower latitude Atlantic region in $\mathrm{P} 2$ compared to P1. For each grid point, the anomaly in the mean $2 \mathrm{~m}$ air temperature is computed that would arise if days with ATL box source region were systematically neglected for both P1 and P2. The P2 - P1 difference in this anomaly can be interpreted as the warming footprint of the ATL box source region for Svalbard in P2 compared to P1. Mathematically this reads

$$
\begin{aligned}
\left(\bar{T}_{\mathrm{P} 2}-\bar{T}_{\neg \mathrm{ATL}, \mathrm{P} 2}\right)-\left(\bar{T}_{\mathrm{P} 1}-\bar{T}_{\neg \mathrm{ATL}, \mathrm{P} 1}\right) \\
=\frac{n_{2}}{N_{2}}\left(\Delta \bar{T}_{\mathrm{ATL}}-\Delta \bar{T}_{\neg \mathrm{ATL}}\right) \\
\quad+\left(\frac{n_{2}}{N_{2}}-\frac{n_{1}}{N_{1}}\right)\left(\bar{T}_{\mathrm{ATL}, \mathrm{P} 1}-\bar{T}_{\neg \mathrm{ATL}, \mathrm{P} 1}\right) .
\end{aligned}
$$

Here, $n_{1}\left(n_{2}\right)$ is the number of ATL box days in P1 (P2), $N_{1}$ $\left(N_{2}\right)$ is the total number of days in P1 (P2), overbars denote temporal average, and $\Delta$ denotes the P2 - P1 difference, respectively. $\bar{T}$ is the mean temperature at a given location and $\bar{T}_{\text {ATL }}\left(\bar{T}_{\neg \text { ATL }}\right)$ is the mean temperature when only considering ATL box days (when neglecting ATL box days), respectively. The expression on the left hand side of (1) translates to the following: "By how much would the temperature rise when taking into account all days, in contrast to when ATL box days were neglected, in P2 compared to P1?" The first term on the right hand side then accounts for the contribution by different temperature trends regarding ATL box source region days and all other source region days. The second term on the right hand side can be interpreted as the amount of warming due solely to enhanced occurrence frequency of ATL box source region days in P2 compared to P1 and is shown in Figure 5(a). The entire presented composite pattern is significantly different from zero at the $99 \%$ confidence level. We find a positive warming contribution by the ATL box advection of up to $0.45 \mathrm{~K}$ over Svalbard, and also most parts of the European Sector of the Arctic are covered with positive (warm) anomalies. While this finding evidences that enhanced advection from the Atlantic has a significant regional warming impact at the surface, the vertical extent of this impact is further analyzed using the Ny-Ålesund long-term radiosonde record (Figure 5(b)). At near surface levels, the magnitude of the warming related to enhanced occurrence of ATL box air is the strongest and agrees well with the reanalysis $(\approx 0.5 \mathrm{~K})$, giving further evidence that atmospheric advection can contribute to surface-amplified warming, as pointed out by [17]. Although the vertical distribution reveals a slight decrease of the ATL box warming footprint towards higher altitudes with bottom-amplified warming and significant warming contributions of at least $0.3 \mathrm{~K}$ up to $\approx 7 \mathrm{~km}$ height, the relative contribution to the overall warming remains fairly constant throughout the entire troposphere. An interesting feature of the vertical ATL footprint in Figure 5(b) is that it is associated with weak but significant cooling roughly above tropopause levels around $11 \mathrm{~km}$. This cooling is attributed to lifting of the mean tropopause height during ATL days as a consequence of the higher vertical extent of the associated warmer tropospheric column over Ny-Ålesund. As a consequence, the weak lapse rate of stratospheric air between $\approx 10$ and $13 \mathrm{~km}$ is substituted by the much stronger negative lapse rate of the troposphere, resulting in an apparent "cooling."

\section{Discussion}

We emphasize that the pattern of temperature anomalies in Figure 5(a) bears strong similarities to the general pattern of Arctic tropospheric winter warming (Figure 1), with the strongest positive trends in the Svalbard region. In addition, the Ny-Ålesund radiosonde measurements indicate that the warming effect due to advection is not limited to the near surface layers but extends throughout the entire troposphere. 


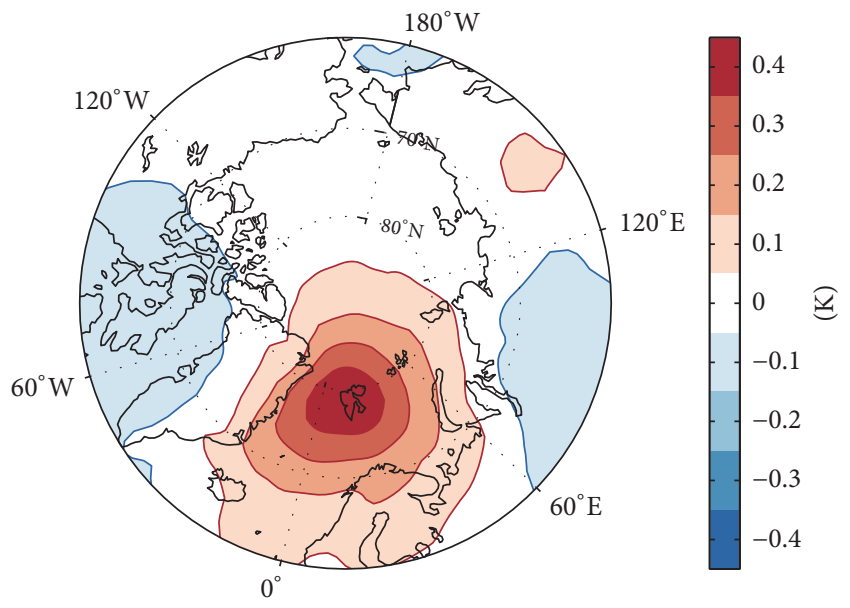

(a)

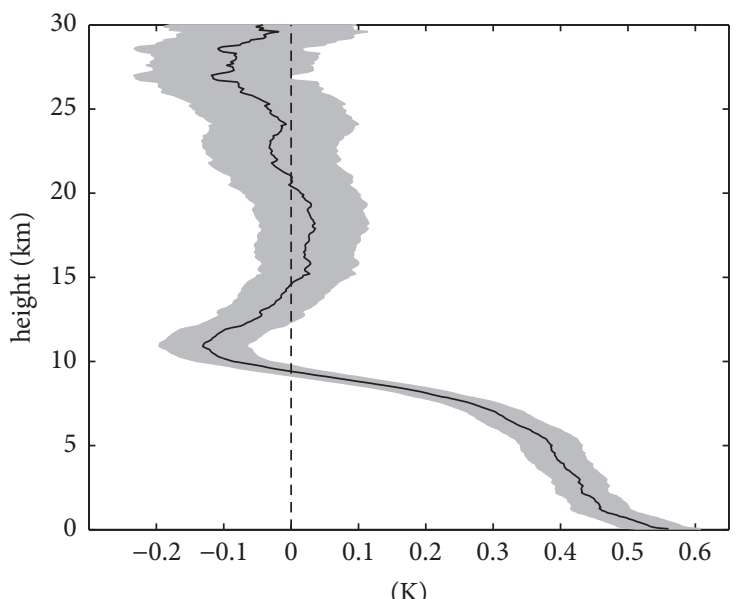

(b)

Figure 5: (a) Difference in $850 \mathrm{hPa}$ temperature between an average day when an ATL-box trajectory reached Ny-Ålesund and an average day for non-ATL-box trajectories, multiplied by the increase in fraction of ATL-box days from P1 to P2 (second term on the right in (1)) for ERA-Interim. (b) The same analysis as (a), but as a vertical plot based on temperatures from the Ny-Ålesund long-term radiosonde record. Grey shading indicates the $95 \%$ confidence level.

However, the positive (but insignificant) trends in the Central Arctic, as well as those over Eastern Siberia and Northern Canada identified in Figure 1 cannot be explained by the warming pattern associated with more frequent air inflow from the Atlantic region (Figure 5(a)), pointing towards a higher relative importance of other warming contributors in these regions. Furthermore, the maximum amplitude of the ATL Box warming pattern is only $+0.45 \mathrm{~K}$ over Svalbard (with another $+0.1 \mathrm{~K}$ warming by reduced advection from the Siberian coastal regions, not shown). Thus, the change in air mass source region explains about one-quarter of the decadal winter warming trend in the Svalbard region. Given that the Arctic is a highly nonlinear system (e.g., [28]), it is perspicuous that even comparably small increases in temperature can project on feedbacks and have amplified impacts. This holds especially for the Svalbard region, where the winter sea ice edge is located (e.g., [5]) with implications for storm tracks, vertical fluxes, and ocean-atmosphere interactions. We hence conclude that the amount of warming due to enhanced air inflow from the ATL box (Figure 5) is meaningful and contributes to explanations regarding why the Svalbard region experiences the strongest recent winter warming. Moreover, the warm and moist air mass advection from the lower latitude Atlantic region is associated with increasing longwave downward radiation due to water vapor and clouds, which continue to affect the Arctic climate even after the actual advection process has ended.

Because of its role as atmospheric gateway to the Arctic, the focus of our study has been set on the North Atlantic sector of the Arctic. Still, a similar trajectory analysis has been repeated for the Alaskan Station Barrow, for which a comparably strong dependence of temperature and water vapor content on the flow direction has been found (Figure 2(b)). However, no consistent trend towards different source regions was found for Barrow (Figure S3(a)). Particularly, unlike for the $\mathrm{Ny}$-Ålesund case, where we could identify the ATL box as a large scale source region with enhanced occurrence frequency in P2, for Barrow's tropospheric air there are no such marked changes apparent. This holds especially for the midlatitude Pacific source regions that are associated with anomalous warm days in Barrow (Figure S3(b)), similar to the North Atlantic source region for NyÅlesund. These findings are in agreement with Barrow's over $50 \%$ weaker winter temperature trend compared to the trend in the Svalbard region (Figure 1).

In general, the Ural blocking high (Figure 4(a)) seems to play an important role in the context of advecting air from lower latitudes towards the Svalbard region. Beyond that, the enhanced occurrence of the so-called Ural blocking in the recent decade has been linked to sea ice retreat in the Barents/Kara Seas $[29,30]$. Given that this link is robust, it would directly feed back on additional sea ice retreat in that region due to both anomalous advection of warm air masses from the south and mechanically pushing pack ice more northward, leaving more open water surfaces in the Barents Sea. Hence, it should be a perspective of future studies to develop process understanding on how the above described circulation changes interact and feed back on other players in the highly nonlinear and warming Arctic climate system.

\section{Conclusions}

The recent winter (DJF) warming trend of the Arctic is the result of a complex interplay of various contributing factors, and its effect maximizes in the North Atlantic region. Our study seeks to quantify the advective contribution to the observed winter warming 1996-2016 in the Svalbard region, where a strong temperature dependence on the 
synoptic flow direction is identified with warmest (coldest) temperatures during southerly (northerly) flow. FLEXTRA air back trajectories for $\mathrm{Ny}$-Ålesund/Svalbard reveal a shift towards warmer source regions of tropospheric air over the analyzed period. This change in air mass advection is associated with sea level pressure patterns that resemble Ural blocking and an intensified Icelandic low, consistent with more frequent southerly flow towards Svalbard and reduced flow from the north. These changes in circulation account for about a quarter $(0.45 \mathrm{~K})$ of the observed near surface winter warming in the Svalbard region from 1996 to 2016. Furthermore, Ny-Ålesund radiosonde data evidence that the corresponding warming footprint extends significantly throughout the entire troposphere, with a vertically constant relative contribution to the overall warming. Essentially, the climate of the Svalbard region as center of the strongest recent winter warming is found to be particularly sensitive to changes in the atmospheric circulation compared to other regions of the Arctic. Future work is needed to physically understand the circulation shift in the first place and to investigate its connection and feedbacks with other warming contributors involving ocean heat transport, sea ice dynamics, and cloud and water vapor radiative effects.

\section{Conflicts of Interest}

The authors declare that there are no conflicts of interest regarding the publication of this article.

\section{Acknowledgments}

The authors gratefully acknowledge the support from the Transregional Collaborative Research Center (TR 172) "ArctiC Amplification: Climate Relevant Atmospheric and SurfaCe Processes, and Feedback Mechanisms (AC)3," which is funded by the German Research Foundation (DFG, Deutsche Forschungsgemeinschaft). The FLEXTRA model was developed by Andreas Stohl (NILU) in cooperation with Gerhard Wotawa and Petra Seibert (Institute of Meteorology and Geophysics, Vienna), and the trajectories are based on meteorological data provided from ECMWF (European Centre for Medium Range Weather Forecast). The trajectories for Ny-Ålesund/Zeppelin Mountain were provided by NILU, and the authors explicitly thank Henrik Grythe (NILU) for support. They also thank Benjamin Segger for discussions regarding the development of the equation. Furthermore, they acknowledge the staff of the AWIPEV Research Base in $\mathrm{Ny}$-Ålesund for launching radiosondes under Arctic conditions. The radiosonde data were taken from doi: 10.1594/PANGAEA.845373 and doi: 10.1594/PANGAEA .875196 .

\section{References}

[1] J. Cohen, J. A. Screen, J. C. Furtado et al., "Recent Arctic amplification and extreme mid-latitude weather," Nature Geoscience, vol. 7, no. 9, pp. 627-637, 2014.

[2] M. C. Serreze and R. G. Barry, "Processes and impacts of Arctic amplification: a research synthesis," Global and Planetary Change, vol. 77, no. 1-2, pp. 85-96, 2011.
[3] J. A. Screen and I. Simmonds, "The central role of diminishing sea ice in recent Arctic temperature amplification," Nature, vol. 464, no. 7293, pp. 1334-1337, 2010.

[4] M. C. Serreze, A. P. Barrett, J. C. Stroeve, D. N. Kindig, and M. M. Holland, "The emergence of surface-based arctic amplification,” The Cryosphere, vol. 3, no. 1, pp. 11-19, 2009.

[5] J. C. Comiso and D. K. Hall, "Climate trends in the Arctic as observed from space," Wiley Interdisciplinary Reviews: Climate Change, vol. 5, no. 3, pp. 389-409, 2014.

[6] H.-S. Park, S. Lee, S.-W. Son, S. B. Feldstein, and Y. Kosaka, "The impact of poleward moisture and sensible heat flux on arctic winter sea ice variability," Journal of Climate, vol. 28, no. 13, pp. 5030-5040, 2015.

[7] A. Hall, "The role of surface albedo feedback in climate," Journal of Climate, vol. 17, pp. 1550-1568, 2004.

[8] V. A. Alexeev, P. L. Langen, and J. R. Bates, "Polar amplification of surface warming on an aquaplanet in "ghost forcing" experiments without sea ice feedbacks," Climate Dynamics, vol. 24, no. 7-8, pp. 655-666, 2005.

[9] R. G. Graversen and M. Wang, "Polar amplification in a coupled climate model with locked albedo," Climate Dynamics, vol. 33, no. 5, pp. 629-643, 2009.

[10] F. Pithan and T. Mauritsen, "Arctic amplification dominated by temperature feedbacks in contemporary climate models," Nature Geoscience Letters, vol. 7, pp. 181-184, 2014.

[11] J. A. Curry, W. B. Rossow, D. Randall, and J. L. Schramm, "Overview of Arctic clouds and radiation characteristics," Journal of Climate, vol. 9, pp. 1731-1764, 1996.

[12] J. M. Intrieri, C. W. Fairall, M. D. Shupe et al., "An annual cycle of Arctic surface cloud forcing at SHEBA," Journal of Geophysical Research: Atmospheres, vol. 107, no. C10, 2002.

[13] J. A. Francis and E. Hunter, "Changes in the fabric of the Arctic's greenhouse blanket," Environmental Research Letters, vol. 2, no. 4, article 045011, 2007.

[14] R. Bintanja and F. M. Selten, "Future increases in Arctic precipitation linked to local evaporation and sea-ice retreat," Nature, vol. 509, no. 7501, pp. 479-482, 2014.

[15] L. Bengtsson, K. I. Hodges, S. Koumoutsaris, M. Zahn, and N. Keenlyside, "The changing atmospheric water cycle in Polar Regions in a warmer climate," Tellus Series A: Dynamic Meteorology and Oceanography, vol. 63, no. 5, pp. 907-920, 2011.

[16] X. Zhang, J. He, J. Zhang et al., "Enhanced poleward moisture transport and amplified northern high-latitude wetting trend," Nature Climate Change, vol. 3, no. 1, pp. 47-51, 2013.

[17] C. Woods and R. Caballero, "The role of moist intrusions in winter arctic warming and sea ice decline," Journal of Climate, vol. 29, no. 12, pp. 4473-4485, 2016.

[18] C. Woods, R. Caballero, and G. Svensson, "Large-scale circulation associated with moisture intrusions into the Arctic during winter," Geophysical Research Letters, vol. 40, no. 17, pp. 47174721, 2013.

[19] B.-M. Kim, J.-Y. Hong, S.-Y. Jun et al., "Major cause of unprecedented Arctic warming in January 2016: Critical role of an Atlantic windstorm," Scientific Reports, vol. 7, article 40051, 2017.

[20] R. G. Graversen, T. Mauritsen, M. Tjernström, E. Källén, and G. Svensson, "Vertical structure of recent Arctic warming," Nature, vol. 451, no. 7174, pp. 53-56, 2008.

[21] M. Maturilli and M. Kayser, "Arctic warming, moisture increase and circulation changes observed in the Ny-Ålesund homogenized radiosonde record," Theoretical and Applied Climatology, pp. 1-17, 2016. 
[22] M. Kayser, M. Maturilli, R. M. Graham et al., "Vertical thermodynamic structure of the troposphere during the Norwegian young sea ICE expedition (N-ICE2015)," Journal of Geophysical Research: Atmospheres, vol. 122, pp. 1-19, 40051.

[23] M. C. Serreze, R. G. Barry, and J. E. Walsh, "Atmospheric water vapor characteristics at $70^{\circ} \mathrm{N}$," Journal of Climate, vol. 8, pp. 719731, 1995.

[24] D. P. Dee, S. M. Uppala, and A. J. Simmons, “The ERA-interim reanalysis: Configuration and performance of the data assimilation system," Quarterly Journal of the Royal Meteorological Society, vol. 137, pp. 553-597, 2011.

[25] A. Stohl, G. P. Wotawa, Seibert., and H. Kromp-Kolb, "Interpolation errors in wind fields as a function of spatial and temporal resolution and their impact on different types of kinematic trajectories," Journal of Applied Meteorology and Climatology, vol. 34, pp. 2149-2165, 1995.

[26] H. N. Cheung, W. Zhou, Y. Shao, W. Chen, H. Y. Mok, and M. C. Wu, "Observational climatology and characteristics of wintertime atmospheric blocking over Ural-Siberia," Climate Dynamics, vol. 41, no. 1, pp. 63-79, 2013.

[27] J. W. Hurrell, Y. Kushnir, G. Ottersen, and M. Visbeck, "Preface," in The North Atlantic Oscillation: Climatic Significance and Environmental Impact, vol. 134 of Geophysical Monograph Series, pp. vii-viii, American Geophysical Union, Washington, D. C., 2003.

[28] J. E. Overland, K. Dethloff, J. A. Francis et al., "Nonlinear response of mid-latitude weather to the changing Arctic," Nature Climate Change, vol. 6, no. 11, pp. 992-999, 2016.

[29] D. Luo, Y. Xiao, Y. Yao, A. Dai, I. Simmonds, and C. L. E. Franzke, "Impact of ural blocking on winter warm Arctic-cold Eurasian anomalies. Part I: Blocking-induced amplification," Journal of Climate, vol. 29, no. 11, pp. 3925-3947, 2016.

[30] T. Gong and D. Luo, "Ural blocking as an amplifier of the Arctic sea ice decline in winter," Journal of Climate, vol. 30, no. 7, pp. 2639-2654, 2017. 

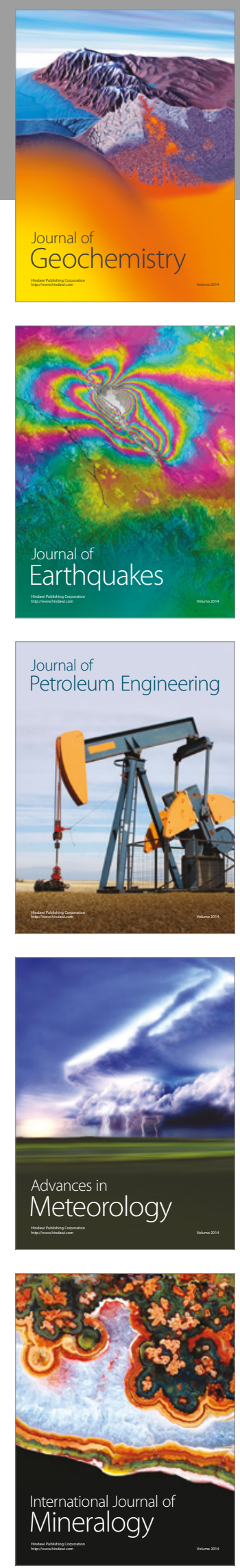
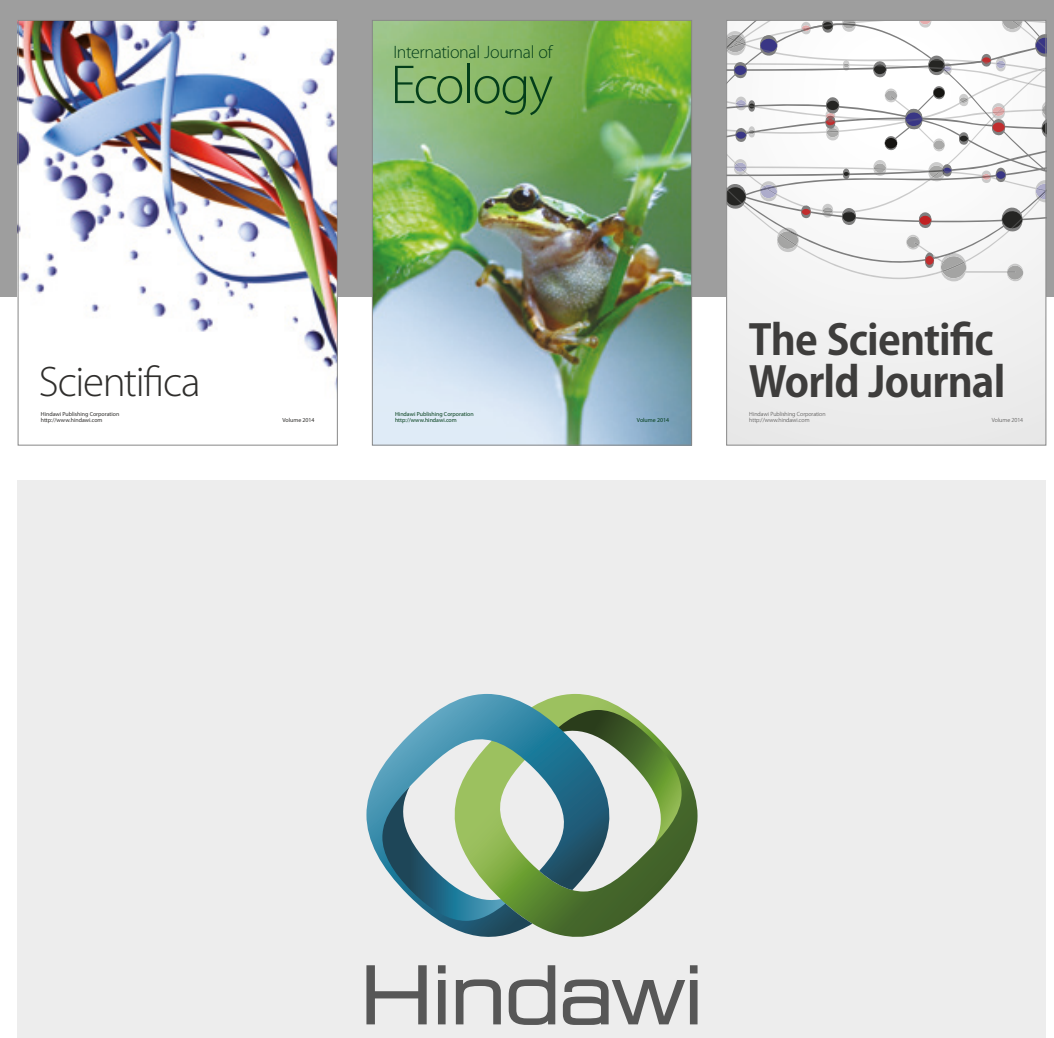

Submit your manuscripts at

https://www.hindawi.com
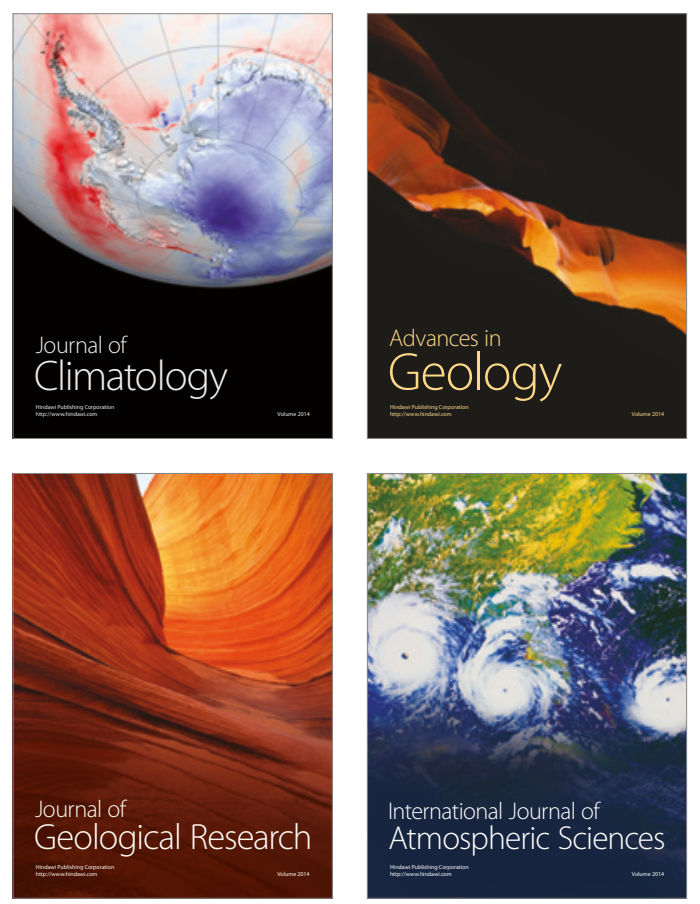

The Scientific

World Journal
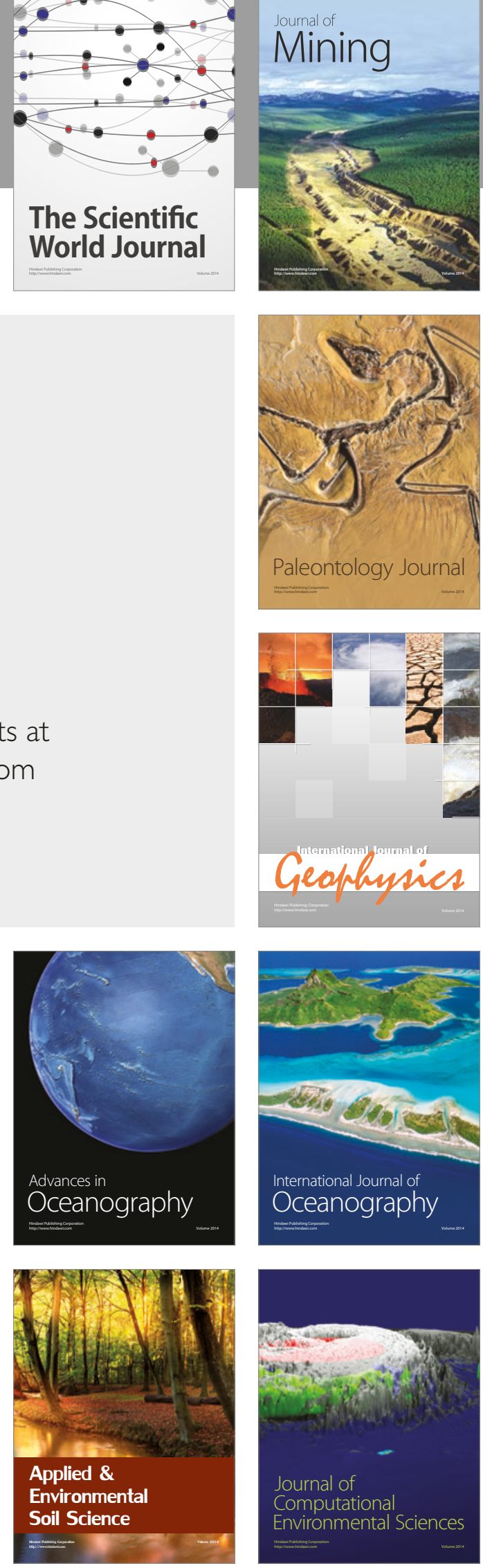